\title{
MITIGACIÓN DE ALTAS SENSACIONES TÉRMICAS DEL MUNICIPIO DE BOSCONIA- CESAR A TRAVÉS DE FORESTACIÓN CON ESPECIES NATIVAS.
}

\author{
Jorge Eduardo Gómez González ${ }^{1}$, Angélica Patricia Vanegas Padilla ${ }^{2}$, Oriana Carolina Jurado Fuentes ${ }^{3}$ \\ Ronny Javier López Hernández ${ }^{4}$.
}

\author{
${ }^{1}$ Ingeniero Ambiental y Sanitario. Contacto: jeduardogomez@unicesar.edu.co \\ ${ }^{2}$ Ingeniera Ambiental y Sanitaria, Esp. Gestión Ambiental. Magíster en Desarrollo Sostenible y Medio Ambiente. \\ Contacto: angelicavanegasp@unicesar.edu.co \\ ${ }^{3}$ Ingeniera Ambiental y Sanitaria, Esp. Geomática. Contacto: orianajurado@unicesar.edu.co \\ ${ }^{4}$ Ingeniero Ambiental y Sanitario. Contacto: ronnylopez@unicesar.edu.co.
}

\begin{abstract}
RESUMEN
Las altas temperaturas o condiciones de sensación térmica revelan inestabilidad en la comunidad Bosconense debido a la presencia de elevados niveles en la zona urbana a causa de la contaminación vehicular, malas prácticas ambientales y topografía desventajosa, alcanzando niveles de "estrés térmico". Se realizó análisis multitemporal de: humedad relativa, temperatura, velocidad del viento, puntos de calor y sensación térmica para los años 2000, 2010, 2015 y 2020. También una caracterización del suelo basada en bibliografías y ambientalistas locales, encontrando 20.694 ha's deforestadas entre 2000-2020 en toda Bosconia. Se presentó metodología de forestación con especies nativas (Cañaguate, Mango, Puy y Roble) y metodología de monitoreo sobre las variables humedad relativa, radiación solar, temperatura y velocidad del viento para evaluar eficacia. Añadiendo monitoreo a la radiación solar para futuras investigaciones locales. Posteriormente, se implementó la forestación y socialización con actores públicos, privados y población aledaña sobre los beneficios y cuidados que deben tenerse, estableciendo los periodos e instrumentos para evaluar la mitigación.
\end{abstract}

Palabras clave: Bosconia; especies nativas; mitigación; monitoreo; sensaciones térmicas.

Recibido: 07 de abril de 2021. Aceptado: 08 de junio de 2021

Received: April 07, 2021. Accepted: June 08, 2021

DOI: https://doi.org/10.33571/rpolitec.v17n34a8

\section{MITIGATION OF HIGH THERMAL SENSATIONS IN THE MUNICIPALITY OF BOSCONIA-CESAR THROUGH FORESTATION WITH NATIVE SPECIES.}

\begin{abstract}
High temperatures or thermal sensation conditions reveal instability in the Bosconense community due to the presence of high levels in the urban area due to vehicular pollution, bad environmental practices and disadvantageous topography, reaching levels of "thermal stress". Multitemporal analysis of: relative humidity, temperature, wind speed, hot spots and thermal sensation was carried out for the years 2000, 2010, 2015 and 2020. Also, a characterization of the soil based on bibliographies and local environmentalists, finding 20,694 ha's deforested between 2000 -2020 throughout Bosconia. Afforestation methodology with native species (Cañaguate, Mango, Puy and Roble) and monitoring methodology on the variables relative humidity, solar radiation, temperature and wind speed were presented to evaluate efficacy. Adding solar radiation monitoring for future local research. Subsequently, afforestation and socialization with public and private actors and the surrounding population about the benefits and care that should be taken was implemented, establishing the periods and instruments to evaluate mitigation.
\end{abstract}


Keywords: Bosconia; native species; mitigation; monitoring; thermal sensations.

Cómo citar este artículo: J.E. Gómez, A.P. Vanegas, O.C. Jurado, R.J. López. "Mitigación de altas sensaciones térmicas del municipio de Bosconia- Cesar a través de forestación con especies nativas" Revista Politécnica vol. 17, no 34 pp. 110-130, 2021. DOI: https://doi.org/10.33571/rpolitec.v17n34a8

\section{INTRODUCCIÓN}

Bosconia es un municipio ubicado en la zona noroccidental del departamento del Cesar en Colombia, cuenta con una población de alrededor de 37.531 personas basado en la proyección del año 2018 del DANE [1], y cuenta también con un área total de 609 kilómetros cuadrados de los cuales 5.49 kilómetros cuadrados representan la zona urbana, una altura promedio de 117 m.s.n.m. y un clima tropical que maneja una temperatura media anual de $32^{\circ} \mathrm{C}[2]$.

Esta zona es reconocida ampliamente en la región caribe por las altas sensaciones térmicas que presenta, ya que debido a varios factores se presentan desde horas tempranas en la mañana hasta las últimas horas de la tarde sensaciones de "calor" muy fuertes y noches "calurosas". Esto se ha intensificado tanto que la población ha adoptado una cultura de evitar salir en la hora pico medio día para evitar estas sensaciones térmicas directamente y el uso de aires acondicionados, el cual es muy alto a nivel doméstico.

Llevándose a cabo una indagación previa de la zona apoyada en la comunidad de los viveros locales y personas impulsadoras del componente ambiental en el Municipio, se concluyó que hace veinte años el municipio en la zona urbana y rural aledaña, presentaba zonas verdes amplias y atractivas paisajísticamente pero con el transcurrir del tiempo muchos de esos predios se utilizaron para construcciones civiles o fueron absorbidas por invasiones de comunidades vulnerables con malas prácticas ambientales que dejaron hoy día el área de Bosconia con alrededor del $50 \%$ de la cobertura arbórea que antes presentaba.

Basado en esto, se hizo la conjetura de que el Municipio está presentando una baja reforestación con respecto a su área, población y su producción de emisiones, generando puntos dentro de la zona urbana con niveles de estrés térmico muy elevados como la zona de "el cruce", "la avenida dos de diciembre", "el estadio", "el antiguo terminal de transporte", "el parque san martín" o "la avenida del hospital". Además, se observó un notorio decremento del paisajismo arbóreo de Bosconia.

Para el mejoramiento del Municipio de forma integral es clave la reforestación en todas las zonas posibles de Bosconia, dándole un enfoque prioritario a las zonas donde las sensaciones térmicas son altas, y sembrando árboles de flora coposa en avenidas y plazas públicas para el embellecimiento del paisaje del Municipio y la reducción de las sensaciones térmicas presentes.

\section{MATERIALES Y MÉTODO}

\section{Determinación de zona de estudio}

En el trabajo que se llevó a cabo en el municipio de Bosconia (Cesar) sobre la reducción de las altas sensaciones térmicas que se presentan, se tomó el área total de Bosconia (urbana y rural) para determinar la población de estudio ya que así se esperó un resultado más efectivo con el objetivo del proyecto (una gran población), y también debido a que determinar hectáreas deforestadas sólo en zona urbana es poco práctico. La población de estudio fueron 20694 hectáreas arbóreas deforestadas desde el año 2000 hasta el año 2020 teniendo en cuenta que "una población es el conjunto de todos los casos que concuerdan con una serie de especificaciones" [3]. 
Para la muestra de esta investigación la cantidad fue de 0,66 hectáreas según la aplicación de la fórmula definida en la investigación "Formula para cálculo de la muestra poblaciones finitas" [4] aplicable para poblaciones finitas como el de las hectáreas que se encontraron:

$$
n=\frac{\mathrm{N} * Z o^{2} * p * q}{d^{2} *(N-1)+Z o^{2} * p * q}
$$

Fórmula para cálculo de muestra de población finita. Fórmula para calcular muestra de población finita.

Donde:

$\mathrm{N}=$ total de la población

$\mathrm{ZO}=1,96$ si la seguridad es del $95 \%$

$\mathrm{P}=$ proporción esperada, $5 \%$ recomendada

$\mathrm{Q}=1-\mathrm{P}$

d=precisión en la investigación, 5\% recomendada.

Debido a que el área de interés del proyecto fue la zona urbana del Municipio se multiplicó el porcentaje de área urbana (del área total de Bosconia) por la muestra para la población total de Bosconia, para obtener así la muestra.

$$
\begin{aligned}
& \text { Ârea Total Bosconia }=609 \mathrm{Km} 2=60900 \mathrm{Ha}^{\prime} \text { s } \\
& \text { Ârea Urbana Bosconia }=5,49 \mathrm{Km} 2=549 \mathrm{Ha}^{\prime} \text { s } \\
& \text { \%. Area Urbana Bosconia } \frac{\text { Area Urbana Bosconia }}{\text { Area Total Bosconia }} \times 100=\frac{5,49 \mathrm{Km}^{2}}{609 \mathrm{Km}^{2}} \times 100=0,9 \% \\
& \text { Muestra Area Total de Bosconia }=\frac{20694 \mathrm{Ha}^{\prime} s * 1,96^{2} * 0,05 * 0,95}{0.05^{2} *(12161-1)+1,96^{2} * 0,05 * 0,95}=73,73 \mathrm{Ha}^{\prime} \mathrm{s} \\
& =73,73 \mathrm{Ha}^{\prime} s \times 0,009=0,66 \mathrm{Ha}^{\prime} s=6600 \mathrm{~m}^{2}
\end{aligned}
$$

Las zonas de muestreo establecidas, con aprobación municipal; fueron el estadio municipal que cuenta con un área total de 3,79 hectáreas, del cual 0,61 hectáreas corresponderán para muestreo; y el parque San Martín que cuenta con un área total de 0,73 hectáreas, del cual 0,08 hectáreas corresponderán para muestreo.

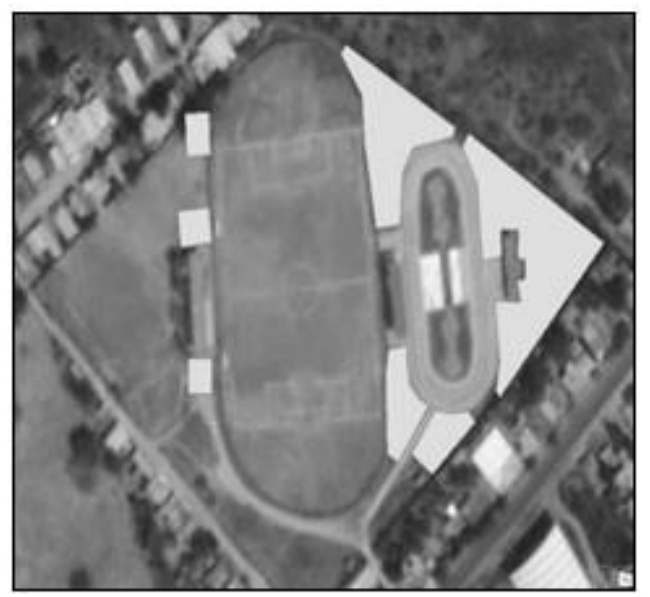

Fig. 1. Zonas de muestreo en estadio Municipal. 


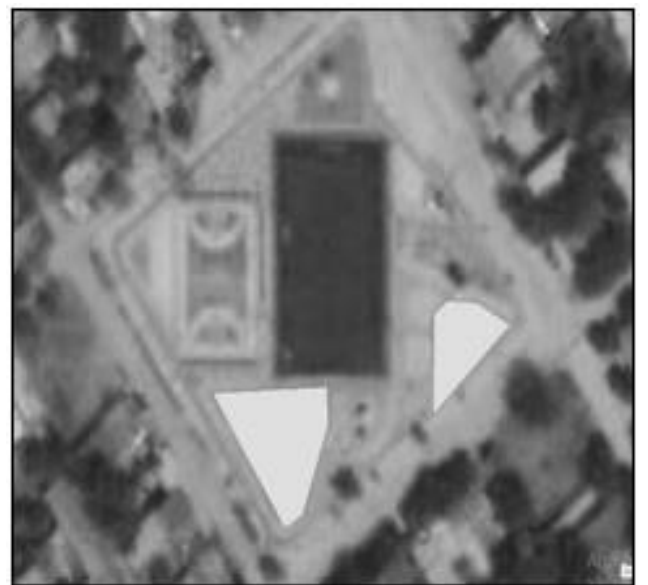

Fig. 2. Zonas de muestreo en parque san martín.

Dentro de las zonas de muestreo no pudieron incluirse "avenida dos de diciembre", "avenida del hospital", "el cruce de Bosconia" y "el terminal de transporte" por proyección de proyectos públicos municipales para esas zonas en el mediano plazo.

\section{ETAPA 1 - Desarrollo de diagnóstico multitemporal de las condiciones y características ambientales del municipio}

\section{Actividad 1.1. Estudio multitemporal de datos de las estaciones meteorológicas aledañas Descripción}

En el desarrollo de esta actividad se solicitó ante el IDEAM los registros históricos de las variables meteorológicas humedad relativa, temperatura, recorrido y velocidad del viento de las estaciones meteorológicas de tipo climática ordinaria ALGARROBO [28045020], GUAYMARAL [28035040] y VILLA ROSA [2835010] [5] por ser las más cercana al Municipio de su tipología. Los datos se analizaron a través del método de estudio "Isoyetas" con el programa geomático ArcGIS para obtener el comportamiento que tuvieron a través del tiempo sobre el municipio, y se usaron para estimar las sensaciones térmicas para el municipio de Bosconia en diferentes años a través de la fórmula de cálculo de Índice de Confort para Colombia en elevaciones menores a 1000 msnm.

$$
I C=\left(36,5-t_{s}\right)\left(0.05+0.04 \sqrt{V}+\frac{n}{250}\right)
$$

Fórmula Índice de Confort Térmico para Colombia en elevaciones menores a 1000 msnm.

Donde "IC" es el índice de confort térmico, "ts" la temperatura y "V" la velocidad del viento.

Hoy en día, para estimar el grado de confort térmico se tienen diferentes métodos tales como los cálculos del poder de refrigeración del cuerpo humano, de la sensación térmica que se experimenta o de una temperatura efectiva o equivalente (ver Tabla 1) [6], que permitieron establecer unos rangos para la clasificación bioclimática.

De esta manera se determinaron las sensaciones térmicas para el área de estudio, teniendo en cuenta la siguiente clasificación bioclimática. 
Tabla 1. Clasificación bioclimática de confort térmico.

\begin{tabular}{|c|c|}
\hline $\mathrm{H}$ & SENSACION EXPERIMENTAL \\
\hline $0 \mathrm{~A} 5$ & INCÓMODAMENTE CALUROSO \\
\hline $5 \mathrm{~A} 10$ & BIENESTAR \\
\hline $10 \mathrm{~A} 15$ & ALFO FRIO \\
\hline $15 \mathrm{~A} 20$ & FRIO \\
\hline MÁS DE 20 & INCÓMODAMENTE FRí \\
\hline
\end{tabular}

\section{Actividad 1.2. Análisis de imágenes satélites del instrumento satelital NOAA-AVHHRR Descripción}

En la realización de esta actividad se requirió la solicitud de la información histórica de los puntos térmicos existentes en Bosconia desde el año 2000 hasta el año 2020 ante la NASA a través del sitio web earthdata.nasa.gov del instrumento satelital AVHHRR que se transporta en los satélites ambientales en órbita polar (POES) de la Administración Nacional Oceánica y Atmosférica (NOAA), y de los instrumentos VIIRS y MODIS que se transportan a través de los satélites Aqua y Terra. A esta información se le realizó un análisis multitemporal obteniendo el incremento de puntos de calor en el Municipio y las causas de aparición de estos.

Paralelamente a través del sitio web earthexplorer.usgs.gov del USGS (Servicio Geológico de Estados Unidos) se descargaron imágenes satelitales LandSAT 7 y LandSAT 8 y se realizó el análisis de cobertura espacial actual y multitemporal de cobertura vegetal del Municipio hallando la población del estudio y el comportamiento o modificación de la cobertura vegetal que se presentó desde el año 2000.

Además, se realizó una comparación del comportamiento de los datos de los diferentes instrumentos satelitales contra los de las estaciones meteorológicas para analizar la relación entre el comportamiento de ambos.

\section{Actividad 1.3. Recolección de información de variedad de flora y calidad de suelo del Municipio de Bosconia, Cesar \\ Descripción}

Esta actividad consistió en hacer una búsqueda intensiva de información técnica e información empírica confiable verificando que hubiese una relación coordinada entre la información encontrada por los dos tipos de fuentes. En la búsqueda de información técnica se presentaron dos formas de búsqueda: física y virtual. De forma física se analizó el Plan de Desarrollo de Bosconia (PDB) y el Esquema de Ordenamiento Territorial de Bosconia (EOT) de los cuales se obtuvo una gran contribución respecto a la información del suelo presente en el Municipio, y también se realizaron entrevistas a expertos del componente ambiental local en la contribución de información referente a la flora local, la cual es escasa.

Se entrevistaron personajes como la Docente en Ciencias Naturales Ángela Castilla, oriunda de Bosconia y líder de múltiples proyectos Educativos Ambientales, entre los cuales, de Fauna y Flora Nativa; José Obredor, uno de los fundadores de Bosconia experimentado en la flora nativa presente previa a la construcción la ferrovía y terrateniente de la zona rural aledaña al Municipio desde el año 1952; y en dos viveros locales de más de 20 años en el Municipio. Además, se realizó un inventario forestal de más de 300 árboles en la zona urbana del municipio para la determinación de las especies predominantes para la determinación de las especies seleccionadas para la forestación.

De forma virtual se pudo tener acceso al mapa de Geología de Colombia del año 2019 a través del Servicio Geológico Colombiano (SGC), y a la investigación "Evaluación hidrogeológica y ambiental del potencial del agua subterránea en la cabecera y área de influencia rural en Bosconia, Cesar" a través de la Universidad De La Salle, información crucial para la caracterización fisicoquímica del subsuelo y suelo en la zona urbana y rural. Además, se consultó en el Instituto de Investigación de Recursos Biológicos Alexander von Humboldt la guía de especies de bosque seco tropical, instituto nacional dedicado a la investigación en biodiversidad y servicios ecosistémicos para la toma de decisiones. 
ETAPA 2 - Formulación del plan de mitigación y monitoreo de altas sensaciones térmicas

Actividad 2.1. Diseño metodológico de forestación estratégica Descripción

Teniendo en cuenta que los espacios abiertos con diferentes características de diseño, morfología y de uso del suelo, varían en su comportamiento microclimático [7]. En el desarrollo de la actividad primeramente se definieron los modelos microclimáticos urbanos presentes en Bosconia utilizando la clasificación implementada en la investigación "El microclima urbano en los espacios abiertos: estudios de casos en Madrid".

Escogiendo las zonas para plantado donde fueron identificados los modelos "VUs" con predominio de la vegetación sin riego sobre los materiales inertes que ocupan al menos el 10\% de la superficie urbana, y "UVs" con predominio de materiales inertes sobre una cobertura de vegetación sin riego que ocupa al menos el $10 \%$ de la superficie. Además, se seleccionó una zona de control para cada modelo microclimático urbano estudiado (para comparación de eficacia del proyecto).

También se seleccionaron las especies arbóreas nativas a implementar en base a la información recolectada sobre las características del suelo y las especies más resistentes al mismo. Posteriormente, se definió la metodología para el sembrado teniendo en cuenta manuales de forestación urbana en conjunto con el asesoramiento del ingeniero forestal Héctor Segura y el equipo técnico de la secretaría de planeación de Bosconia teniendo en cuenta las necesidades para los espacios y de los especímenes arbóreos con respecto al ahoyado, abonado y plantado.

\section{Actividad 2.2. Diseño metodológico de monitoreo y mantenimiento}

Durante esta actividad se definieron los periodos de tiempo para la replantación de especímenes muertos y el mantenimiento a los mismos, las variables a monitorear, sus respectivos instrumentos de medición y los periodos de tiempo de monitoreo, al igual que la metodología para la evaluación teórica de la eficiencia de la mitigación de las altas sensaciones térmicas.

Se seleccionarán las variables e instrumentos de medición necesarios para mediante una revisión periódica evaluar la efectividad del plan de mitigación, así como las actividades necesarias para el mantenimiento de la siembra realizada.

\section{ETAPA 3 - Implementación del plan de mitigación y monitoreo de altas sensaciones térmicas}

\section{Actividad 3.1. Trámites y permisos}

En el desarrollo de esta actividad se realizó la gestión pertinente ante los entes Municipales públicos y privados, y se definió su participación en el desarrollo del proyecto; se solicitaron los diferentes permisos y requisitos necesarios para proceder en la modificación con árboles de espacios que lo ameriten, dispuestos en la vía pública. Y para el mismo fin ante los predios privados que lo ameriten.

En el desarrollo de esta actividad se definieron los actores participantes del proyecto y se realizaron los modelos de solicitud de permisos y participación.

\section{Actividad 3.2. Socialización del proyecto}

La socialización del proyecto se realizó ante todos los actores participantes del proyecto como los propietarios de los predios de las áreas a forestar, entidades colaboradoras, la población inmediata a las zonas a forestar y con el personal de trabajo con que se desarrolló las labores de sembrado detrás del plan de forestación a los cuales se les dejó en claridad el enfoque técnico, los beneficios y las responsabilidades detrás de la actividad de forestar.

\section{Actividad 3.3. Forestación en el Municipio de Bosconia}

Esta actividad constó del sembrado estratégico de los árboles seleccionados, en los lugares predispuestos aprobados para siembra, abonando el terreno y plantando el espécimen según lo diseñado en cada zona designada. 


\section{RESULTADOS}

ETAPA 1 - Desarrollo de diagnóstico multitemporal de las condiciones y características ambientales del municipio

Actividad 1.1. Estudio multitemporal de datos de las estaciones meteorológicas aledañas

Como resultado del estudio histórico de las estaciones ALGARROBO [28045020], GUAYMARAL [28035040] y VILLA ROSA [2835010] se obtuvo la incidencia de la temperatura, la humedad relativa y el viento en el Municipio para los años 2000, 2010 y 2015 excluyendo los datos del 2020 ya que aún no están disponibles. El estudio se planificó para estudiar cada 10 años desde el 2000, exceptuando la última década que se dividió en dos quinquenios (periodos de 5 años) debido a la gran incidencia que tuvo con respecto a la década previa.

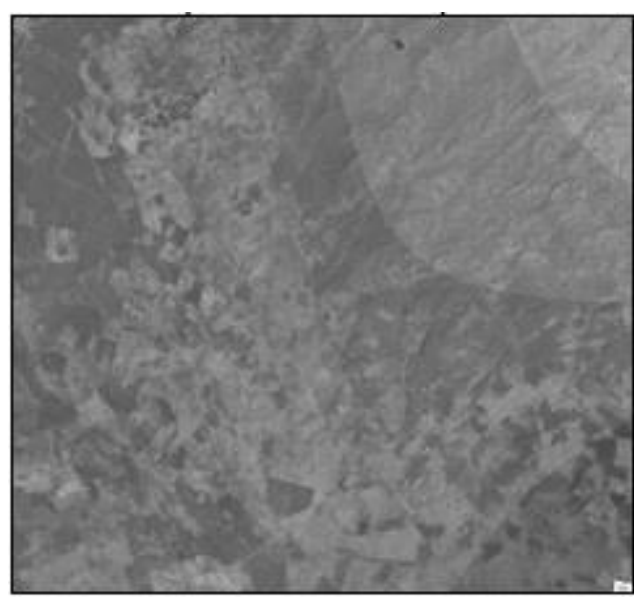

Fig. 3. Análisis de temperatura año 2000.

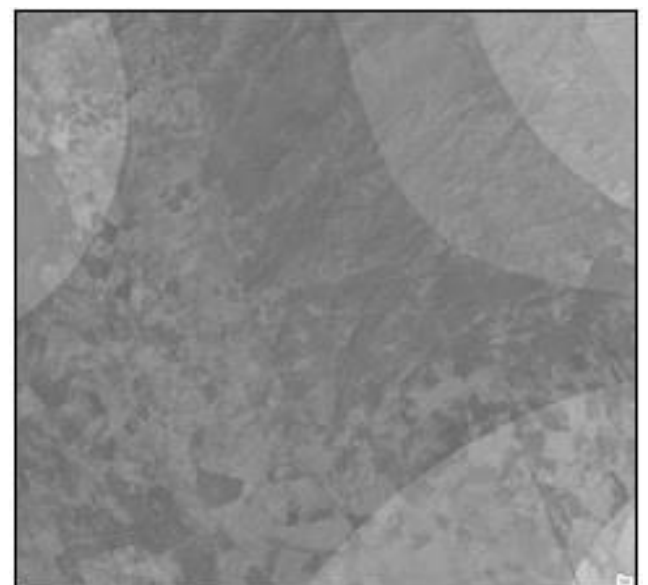

Fig. 4. Análisis de temperatura año 2010. 


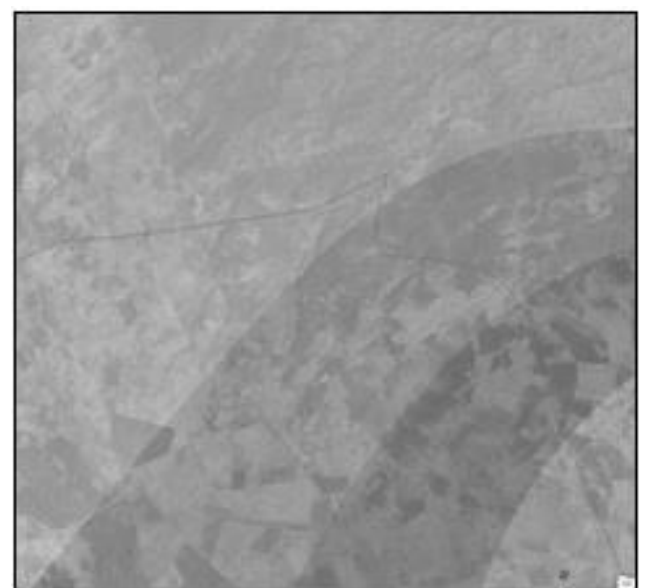

Fig. 5. Análisis de temperatura 2015.

\section{Humedad relativa}

En el análisis de la humedad relativa se encontró que no fue significativa la variación desde el año 2000 hasta el año 2010 presentando valores de entre 63\%-64\% de humedad relativa, pero para el año 2015 hubo un descenso de entre un $4 \%$ a un $5 \%$ arrojando resultados de humedad relativa de $58 \%-60 \%$. El descenso de la humedad relativa frente al incremento de la temperatura estimula la sudoración corporal debido a que el aire no está saturado de vapor de agua, indicando que se está generando un estrés térmico considerable para una persona.

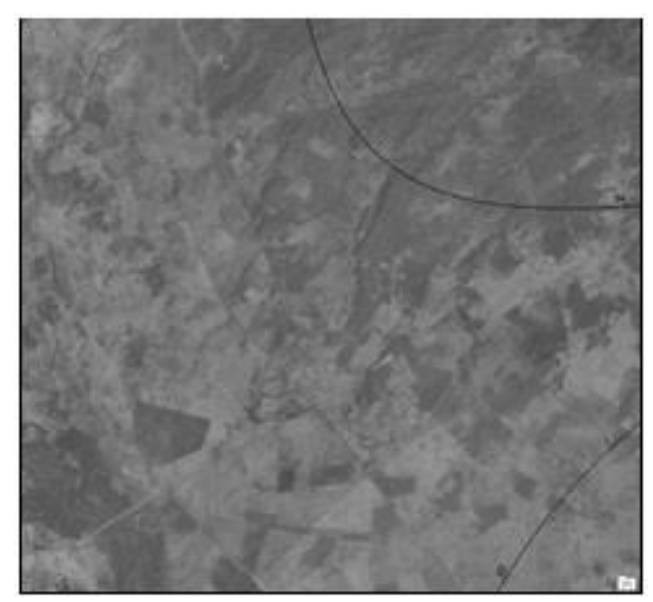

Fig. 6. Análisis humedad relativa 2000. 


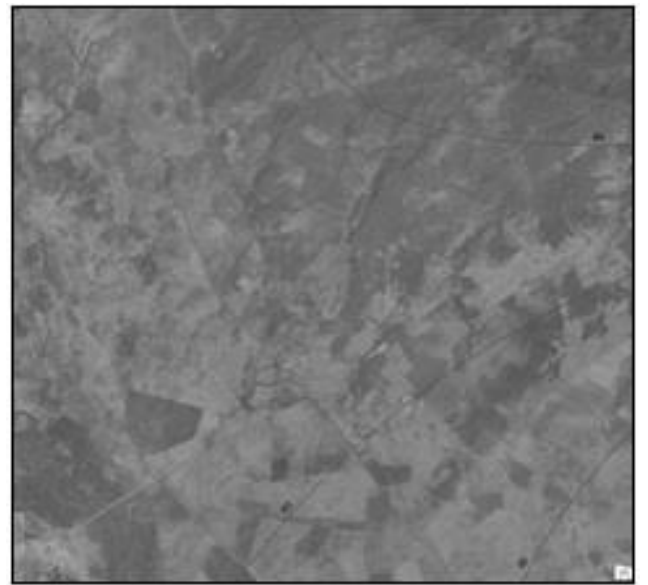

Fig. 7. Análisis humedad relativa 2010.

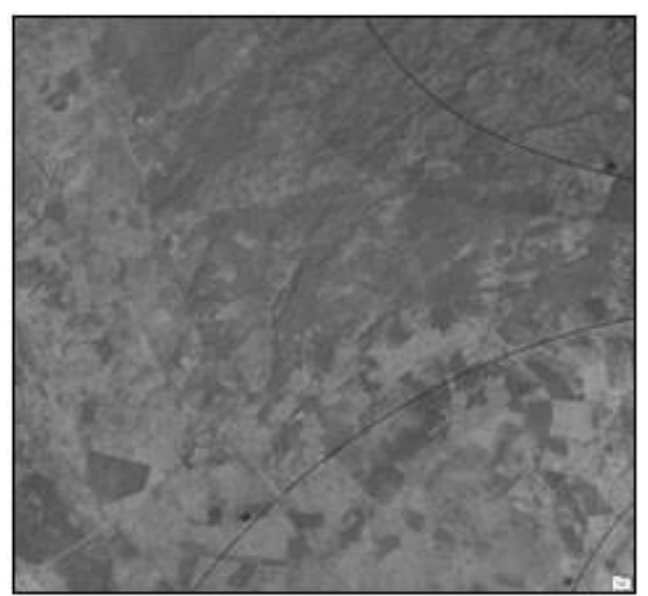

Fig. 8. Análisis humedad relativa 2015.

\section{Viento}

En el desarrollo del análisis del viento se pudo apreciar que no ha habido un cambio significativo desde los años 2000 hasta el 2015 en la zona urbana de Bosconia presentando velocidades de $2-5 \mathrm{~km} / \mathrm{h}$, debido a que las corrientes de aire son mayormente influenciadas por la topografía del terreno y la modificación estimada de la topografía ha sido de muy baja a nula.

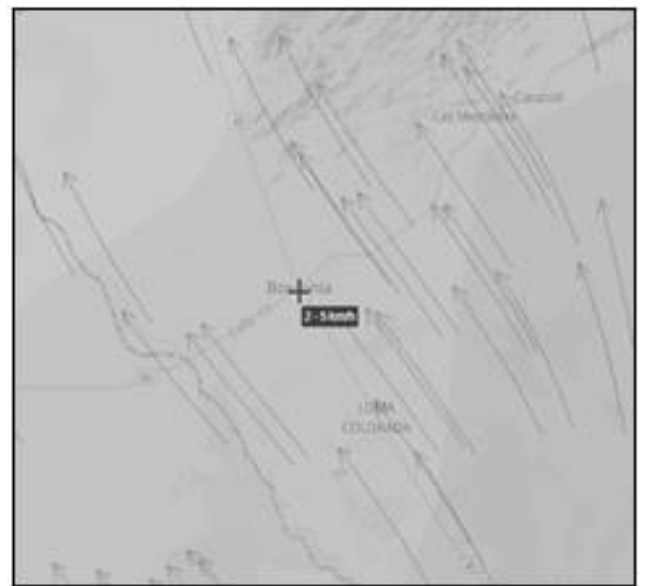

Fig. 9. Análisis velocidad del viento 2000. 


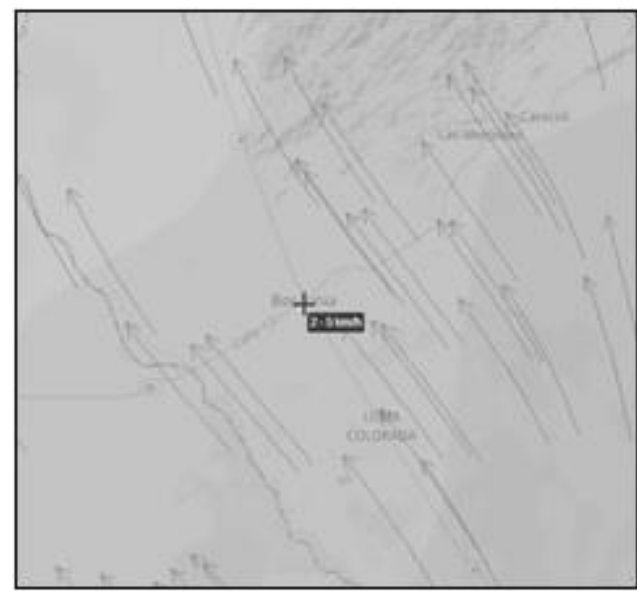

Fig. 10. Análisis velocidad del viento 2010.

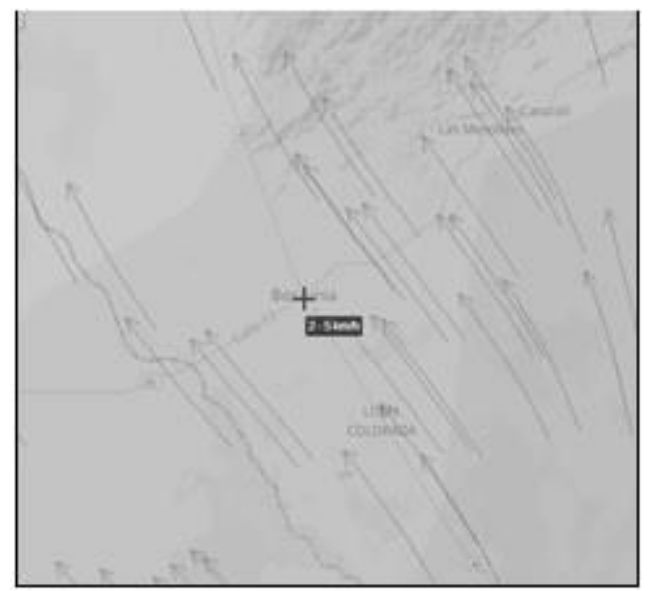

Fig. 11. Análisis velocidad del viento 2015.

\section{Sensación térmica}

En los análisis de sensación térmica para los años 2000, 2010 y 2015 la variación en la zona urbana fue menor a 1 en la escala de clasificación bioclimática (ver Tabla 1), por lo cual las isolíneas no fueron apreciables en el software.

Se determinó que para el año 2000 en la zona urbana central y sur se encontraron sensaciones térmicas de 2.24 a 2.26 y para la zona norte sensaciones térmicas de 2.26 a 2.27. Para el año 2010 se presentaron sensaciones de 1.69 a 1.78 en toda la zona urbana, dándose las mayores sensaciones térmicas al noroeste del Municipio, Para el año 2015 se encontró que la sensación térmica se mantuvo en valores de 1.69 a 1.78, e igualmente las sensaciones térmicas más altas se mantuvieron al noroeste del Municipio. 

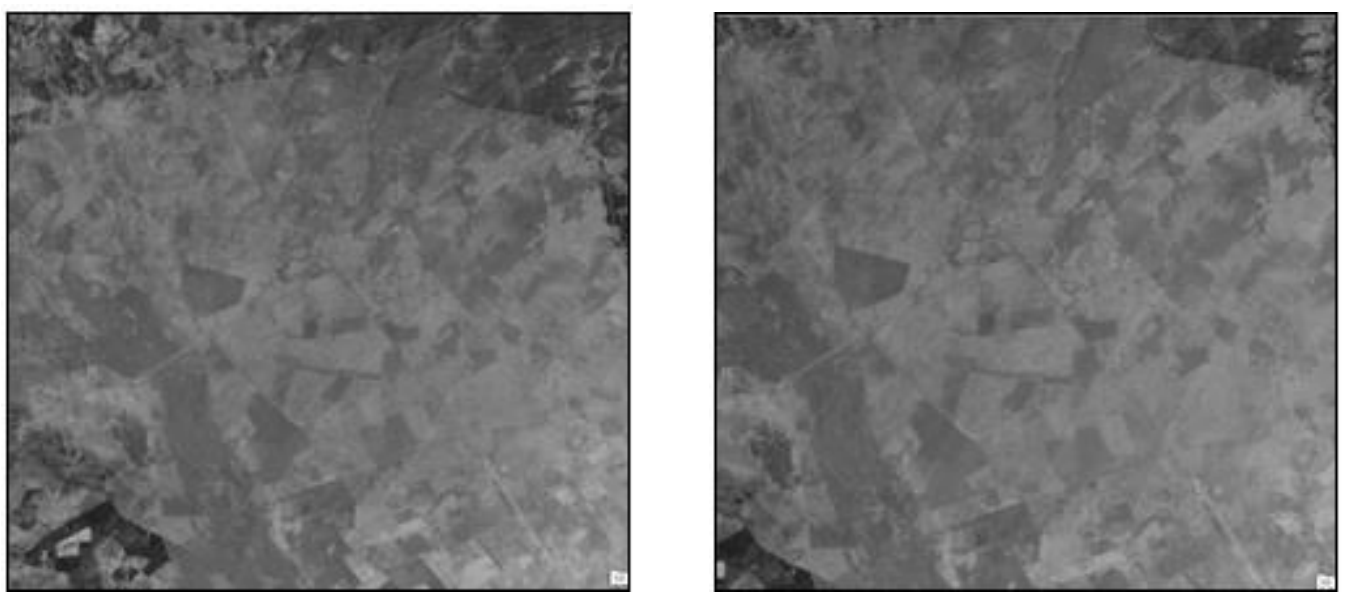

Fig. 12. Análisis de sensación térmica 2000. Fig. 13. Análisis de sensación térmica 2010.

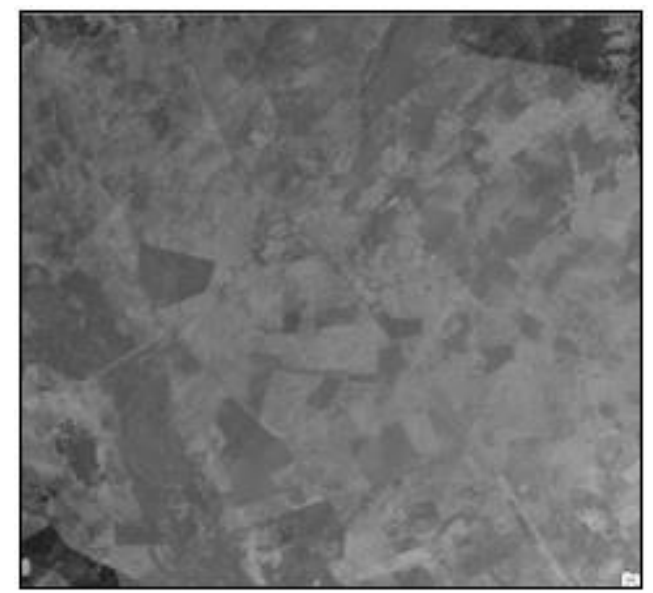

Fig. 14. Análisis de sensación térmica 2015.

Actividad 1.2. Análisis de información satelital de los instrumentos satelitales AVHHRR, VIIRS, MODIS, LandSAT 7 y LandSAT 8

El desarrollo de esta actividad arrojó como resultado, el análisis de los puntos de calor encontrados con los instrumentos satelitales AVHHRR, VIIRS y MODIS a los años 2010, 2015 y 2020. Se exceptuó el año 2000 ya que presentó sólo un punto de calor ubicado en el borde oeste del Municipio (de poca incidencia sobre la zona urbana) y se necesitan al menos dos para poder realizar un análisis confiable.
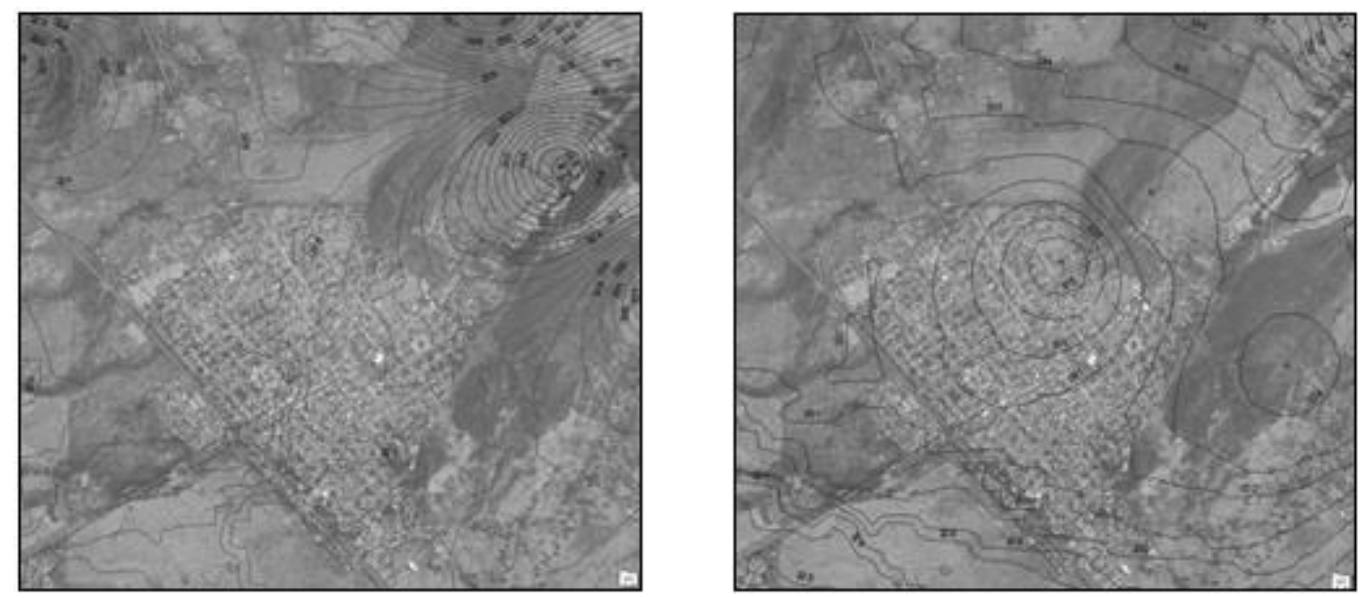
Fig. 15. Análisis puntos de calor 2010. $\quad$ Fig. 16. Análisis puntos de calor 2015.

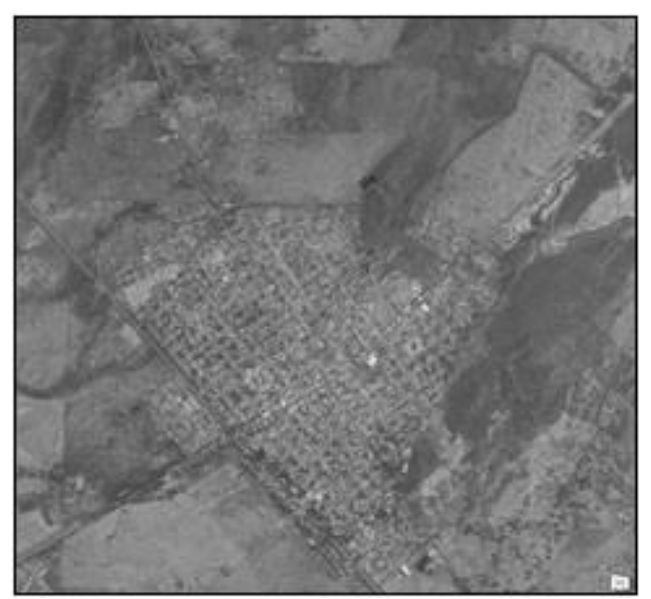

Fig. 17. Análisis puntos de calor 2020.

Para el año 2010, se encontraron niveles de radiación solar de 325 en toda la zona sur y hacia la zona este central, de 326 hacia la zona noreste y 327 en la zona norte y noroeste. Estos niveles se incrementan hacia el oeste que para el año 2010 estaba deforestada para uso agrícola y se disminuían hacia el este, zona de vegetación densa arbórea para el año 2010 (previamente a la minería).

En el año 2015, los niveles de radiación se incrementaron a 331 hacia la zona sur y central urbana y 332 hacia la zona norte llegándose a presentar un punto de calor directamente dentro de la zona urbana noreste de 328 y un punto de calor en el borde sur este de 334, zona donde se ejecutan actividades mineras.

Y para el año 2020 la zona sur presentó valores de radiación de 332, la zona central y central-norte valores de 333 y el norte de la zona urbana valores de 334.

Al momento de observar todos los años en conjunto se identifica claramente el incremento de la radiación solar sobre la zona urbana de Bosconia siendo esta también influyente sobre nuestra percepción de sensación térmica. En el estudio de las imágenes satelitales, se pudo obtener la cobertura vegetal actual y multitemporal usando la metodología CORINE Land Cover para determinación de coberturas oficial en Colombia a una escala 1:100.000.

Debido a que sólo de la zona urbana generaba un margen de error muy amplio, entonces, se determinó la población de estudio del área total del Municipio y sucesivamente la muestra para esa población (obteniendo así una población y muestra mayor a la que podría obtenerse de la zona urbana que representa el $0,9 \%$ del área total).

Se usaron para los años 2000 y 2010 imágenes Landsat 7 debido a que las imágenes Landsat 8 (que cuentan con una mayor resolución) no tienen datos disponibles para estos años, utilizando la mezcla de bandas 4-3-2, recomendada para análisis de cobertura vegetal por la distinción visual que genera de la cobertura vegetal, quedando esta en color rojo entre más densa sea. 


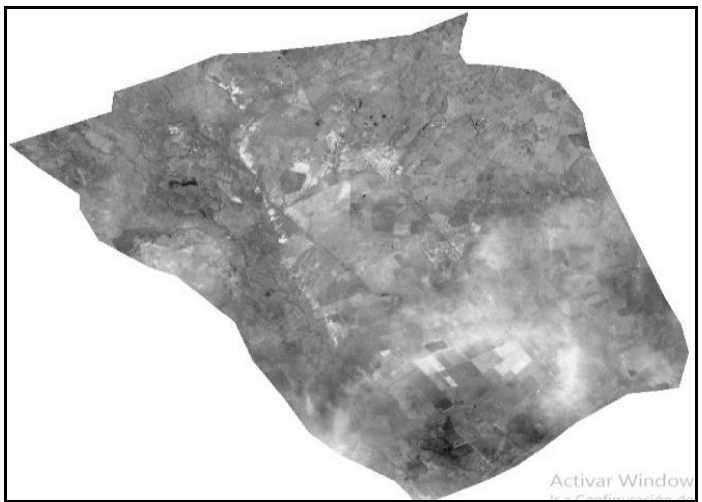

Fig. 18. Análisis de cobertura vegetal del año 2000 con mezcla de bandas 4-3-2 de imagen Landsat 7.

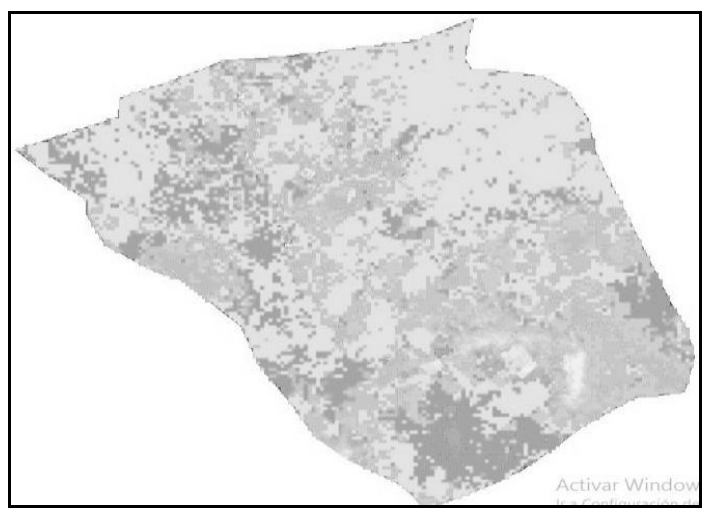

Fig. 19. Análisis de cobertura vegetal del año 2000 con clasificación CORINE Land Cover escala 1:100.000.

Para el año 2000 se encontró una cobertura arbórea entre bosque denso y bosque fragmentado de 36884,97 hectáreas. Siendo una arborización poco golpeada por la agricultura hacia la zona norte, donde se presentó la mayor cantidad de cobertura arbórea.

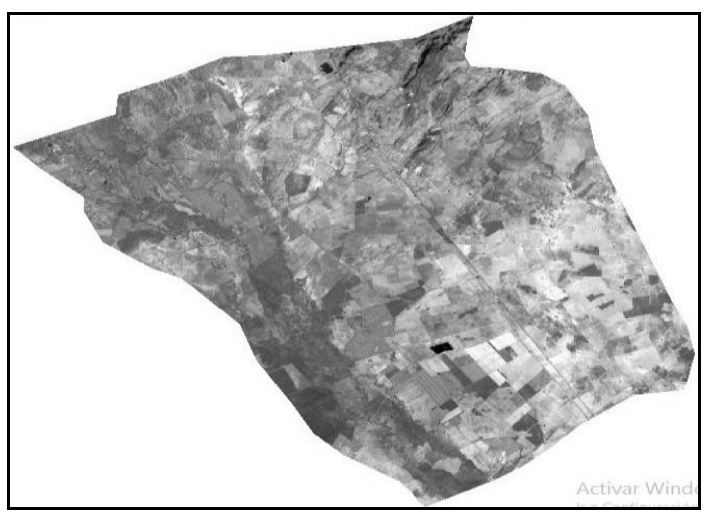

Fig. 20. Análisis de cobertura vegetal del año 2010 con mezcla de bandas 4-3-2 de imagen Landsat 7. 


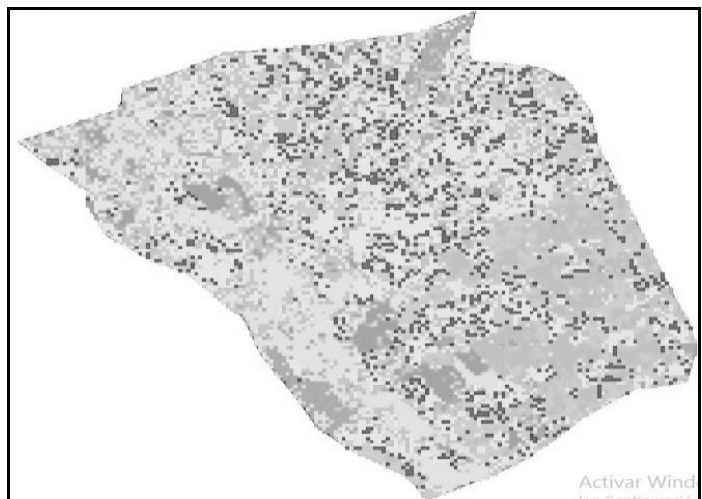

Fig. 21. Análisis de cobertura vegetal del año 2010 con clasificación CORINE Land Cover escala 1:100.000.

Para el año 2010 se obtuvieron 24724,17 ha de cobertura arbórea, manteniéndose predominando el bosque denso sobre el bosque fragmentado. En años 2015 y 2020 se utilizaron imágenes Landsat 8 que cuentan con una resolución de 16 bits por pixel, utilizando la mezcla de bandas 6-5-4, recomendada para análisis de cobertura vegetal en imágenes Landsat 8 por la distinción visual que genera de la cobertura vegetal, quedando esta en color rojo entre más densa sea.

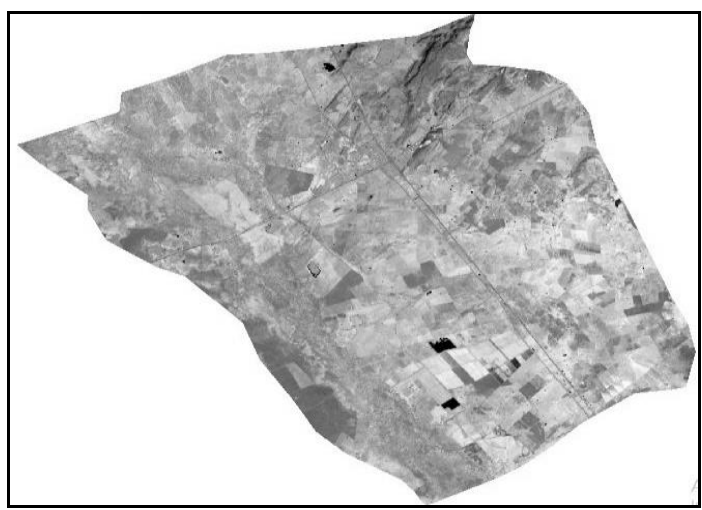

Fig. 22. Análisis de cobertura vegetal del año 2015 con mezcla de bandas 6-5-4 de imagen Landsat 8.

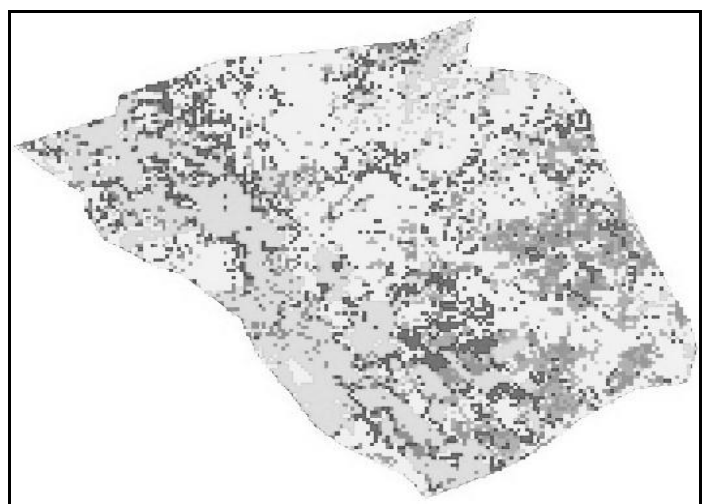

Fig. 23. Análisis de cobertura vegetal del año 2015 con clasificación CORINE Land Cover escala 1:100.000.

En el análisis del año 2015 se obtuvieron 18921,35 ha entre bosque denso y fragmentado, además de 7654 ha de terreno sin o con poca vegetación. 


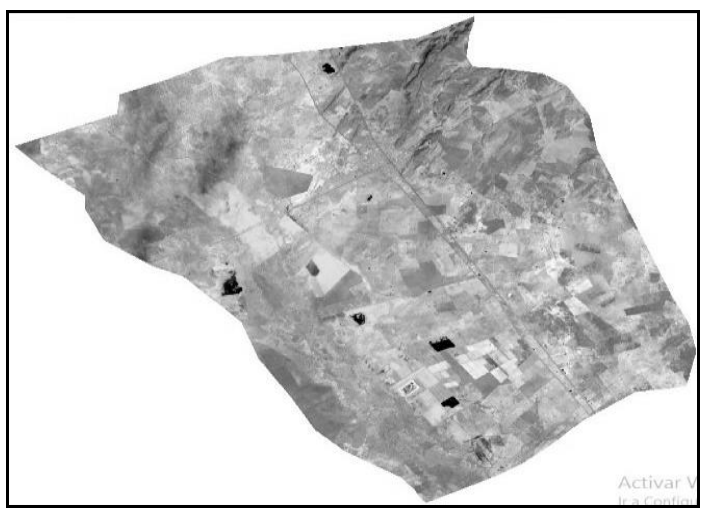

Fig. 24. Análisis de cobertura vegetal del año 2020 con mezcla de bandas 6-5-4 de imagen Landsat 8.

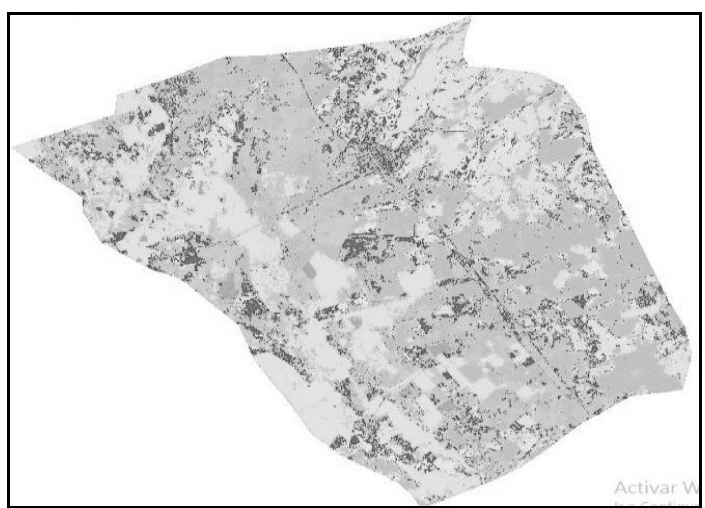

Fig. 25. Análisis de cobertura vegetal del año 2020 con clasificación CORINE Land Cover escala 1:100.000.

En el año 2020 se encontraron 16190,46 ha de cobertura arbórea (bosque denso y fragmentado), y un área significativa sin vegetación de 16201,44 ha.

Al realizar el análisis multitemporal de los años seleccionados como representativos se pudo obtener que el descenso de vegetación arbórea desde el año 2000 hasta el año 2020 fue de 20694,51 ha, una importante cifra ya que representa el $33 \%$ del área total del Municipio.

\section{Actividad 1.3. Recolección de información de variedad de flora y calidad de suelo del Municipio de Bosconia, Cesar \\ Descripción}

Esta actividad dio como resultado la determinación de especies nativas ideales para el cumplimiento del objetivo del proyecto en Bosconia encontrando como predominante desde antes de los años 50 al árbol de "Bálsamo".

Se encontraron otras especies nativas como roble rosado, puy, cañaguate, acacia, mango; las cuales se clasificaron teniendo la guía de especies [8]. Además, es resaltable que dentro del inventario forestal que se realizó con más de 300 árboles de forma aleatoria en Bosconia predominaron especies introducidas como olivo negro, neem y maíz tostao',

El municipio de Bosconia presenta subsuelos cuaternarios [9] (ver Fig. 28), y suelos bien drenados, superficiales, limitados por sales y carbonato de calcio, pobre en carbón orgánico, normales en fósforo y potasio [10]. 


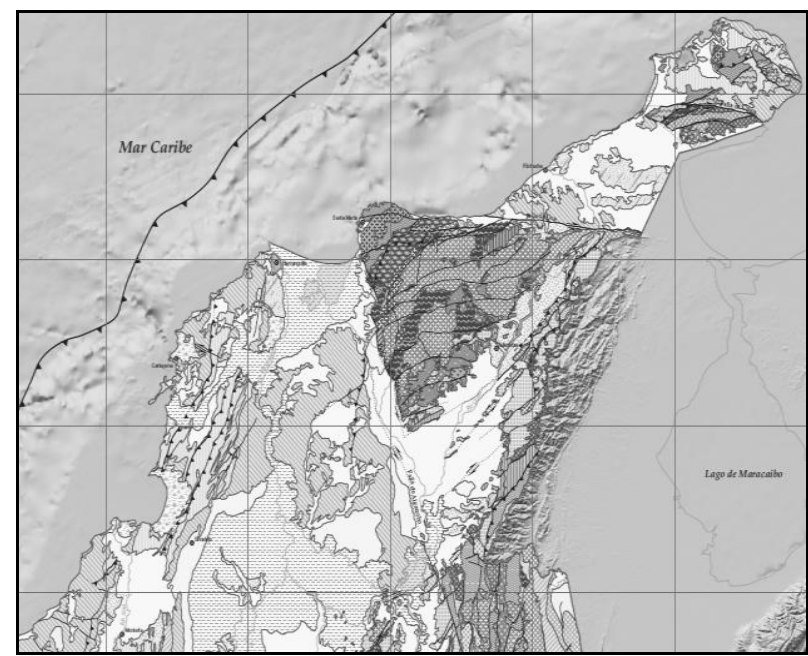

Fig. 26. Mapa geológico de zona norte de Colombia 2019.

ETAPA 2 - Formulación del plan de mitigación y monitoreo de altas sensaciones térmicas

\section{Actividad 2.1. Diseñar metodología de forestación estratégica}

Como resultado de esta actividad, se definió en el plan de forestación que la zona del estadio municipal y la zona del antiguo terminal de transporte obedecen al modelo microclimático urbano "VUs" por lo cual se escogió la zona del estadio como zona de plantado y la zona del terminal de transporte como punto de control para comparar la eficacia de la mitigación.
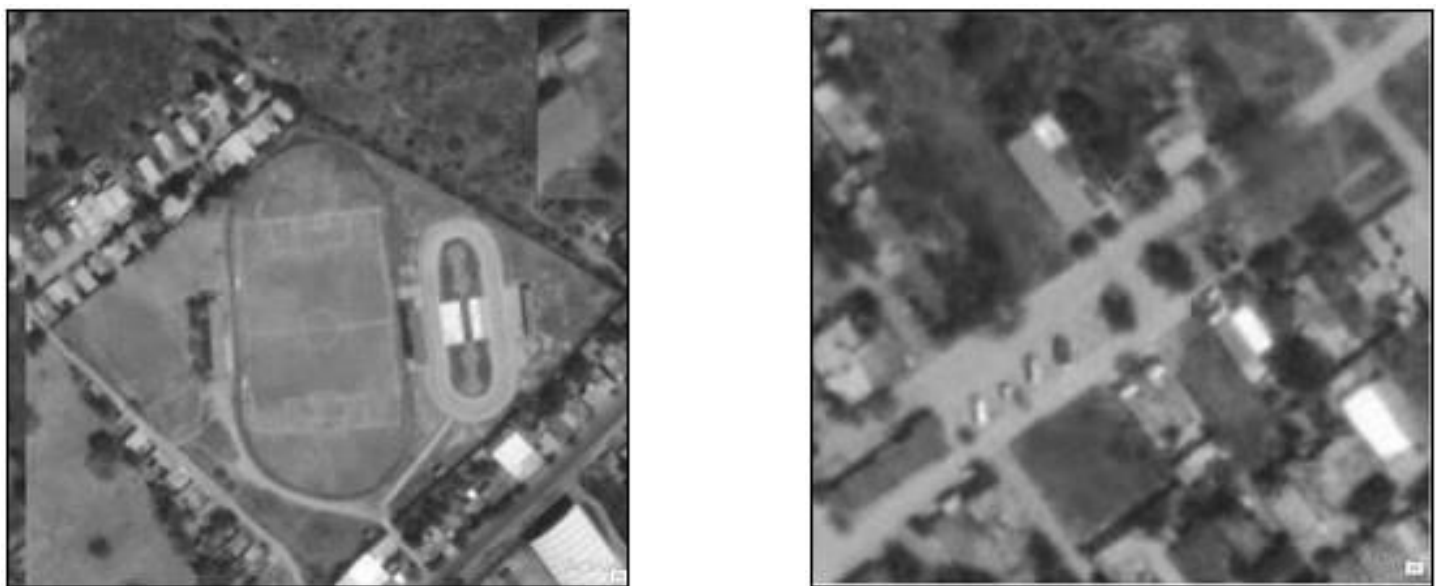

Fig. 27. Zona de plantado en estadio municipal. Fig. 28. Zona de control en "Avenida del Hospital".

También, se determinó que la zona del parque san martín y la avenida del hospital presentan el modelo "UVs" por lo cual, se seleccionó la zona del parque san martín como zona de plantado y la avenida del hospital como punto de control para esta. 

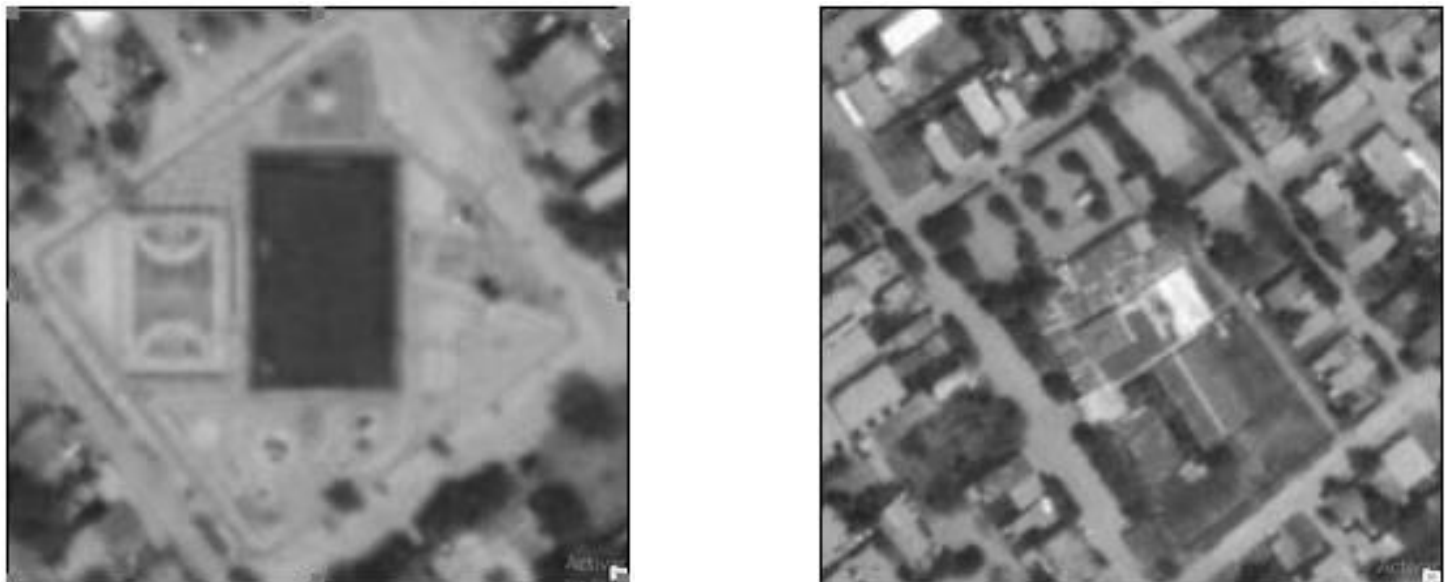

Fig. 29. Zona de plantado en parque San Martín. Fig. 30. Zona de control en "Avenida del Hospital”.

Paralelamente, se seleccionaron 4 especies arbóreas para implementar en la mitigación de las altas sensaciones térmicas. En los criterios de selección de las especies se tuvo en cuenta que los árboles fueran maderables, ya que estos presentan menos exigencias de agua, y también, que estos tuviesen raíz primaria y una alta esperanza de vida en suelos arcillosos con un buen drenado. Además, que tuvieran una densidad de follaje de media a alta y una amplitud de copa mayor a $7 \mathrm{~m}$.

Una de las especies seleccionadas fue puy (Tabebuia impetiginosa) con una amplitud de copa de 7-14 metros, una densidad de follaje media y altura máxima mayor a $20 \mathrm{~m}$. La especie Cañaguate (Handroanthus chrysanthus) con una amplitud de copa mayor a 14 metros, una densidad de follaje media y una altura máxima mayor a $14 \mathrm{~m}$. La especie roble rosado (Tabebuia rosea) con una amplitud de copa mayor a $14 \mathrm{~m}$, una densidad de follaje media y una altura máxima mayor a $40 \mathrm{~m}$. Y la especie mango (Mangifera indica) con una amplitud de copa mayor a $14 \mathrm{~m}$, densidad de follaje alta y altura máxima mayor a $40 \mathrm{~m}$.

Posteriormente se definió que en el sembrado de los árboles el ahoyado se hiciera con una profundidad de $40 \mathrm{~cm}$ y un diámetro de $35 \mathrm{~cm}$, para garantizar que los especímenes sembrados tuviesen un volumen amplio de tierra removida. También, se estimó que el abonado en el hoyo fuese $80 \%$ abono (de estiércol, arena y aserrín) y $20 \%$ tierra extraída del hoyo para que el árbol tenga una garantía de nutrientes mientras se adapta al suelo presente en su etapa inicial de crecimiento.

Además, se estableció que durante el plantado se garantizara que la dirección de la raíz fuese hacia abajo para evitar que crezca de forma diagonal u horizontal para reducir riesgo de daños a infraestructuras. Además, se definió un replanteo de los especímenes muertos a los dos meses de la plantación, analizando por qué no sobrevivieron y tomando las respectivas correcciones en el sembrado.

\section{Actividad 2.2. Diseñar metodología de monitoreo y mantenimiento.}

En el plan de monitoreo y mantenimiento diseñado se definió un periodo de replantación cada 4 meses para los especímenes que no sobrevivan y la toma de medidas que garanticen el crecimiento del árbol replantado haciendo una evaluación de los factores que incidieron sobre este. Además, se seleccionó un periodo de tiempo para reguío de cada 2 a 3 días durante los primeros 10 meses y abonado recomendable cada 3 meses.

También, se determinó que para la mitigación de las altas sensaciones térmicas se monitorearan las variables: humedad relativa, radiación solar, temperatura y velocidad del viento. Aunque en el presente estudio no se utiliza la variable radiación solar para el cálculo del índice de sensación térmica se consideró su monitoreo ya que hay numerosas fórmulas que consideran de 2 a 4 variables de las definidas, por lo que servirá de apoyo para otras investigaciones locales sobre esta nueva área de investigación. 
Como instrumento de monitoreo se seleccionó principalmente un medidor de estrés térmico ya que puede monitorear las 4 variables a la vez, es de fácil obtención y presenta una oferta económica viable. Como alternativa a esta herramienta se consideraron el higrómetro para la humedad relativa, el luxómetro para la radiación solar, el termómetro digital para la temperatura y el anemómetro para la velocidad del viento.

Tabla 2. Instrumentos de medición de variables.

\begin{tabular}{|c|c|c|}
\hline VARIABLE & $\begin{array}{l}\text { INSTRUMENTO } \\
\text { DEMONITOREO }\end{array}$ & \\
\hline HUMIEDAD RELATIVA & HIGRÓMETRO & \multirow{4}{*}{$\begin{array}{l}\text { MEDIDOR DE } \\
\text { ESTRÉS TÉRMICO }\end{array}$} \\
\hline RADIACIÓN SOLAR & LUXÓMETRO & \\
\hline TEMPERATURA & $\begin{array}{l}\text { TERMÓMETRO } \\
\text { DIGITAL }\end{array}$ & \\
\hline $\begin{array}{l}\text { VELOCIDAD DEL } \\
\text { VIENTO }\end{array}$ & ANEMÓMETRO & \\
\hline
\end{tabular}

Para obtener el valor de mitigación de sensaciones térmicas se recomienda la medición "in situ" cada 3 meses de las variables con al menos 5 repeticiones por punto de medición para obtener un valor confiable, ya que son variables de muy fácil alteración o variación. También se recomienda un punto de medición por cada $100 \mathrm{~m} 2$ en las zonas de muestreo.

\section{ETAPA 3 - Implementación del plan de mitigación y monitoreo de altas sensaciones térmicas}

\section{Actividad 3.1. Trámites y permisos}

Durante el desarrollo de esta actividad se tramitó el permiso para siembra en las zonas de Bosconia-Cesar con el apoyo del equipo técnico de la secretaría de planeación definiendo una cantidad de árboles, las especies seleccionadas y los puntos de siembra. Se aprobó una cantidad de 19 árboles en el estadio municipal y 6 árboles en el parque San Martín. Una vez obtenido el permiso de siembra se diseñó y diligenció un formato de invitación a los actores participantes interesados (alcaldía municipal, ASOREBOS, cuerpo de bomberos, BIOGER S.A. E.S.P, defensa civil y policía ambiental) los cual fueron recibidos y tramitados internamente obteniendo una respuesta positiva por las entidades.

\section{Actividad 3.2. Socialización del proyecto}

Para garantizar que el proyecto tuviese permanencia se socializó con la comunidad aledaña a las zonas de muestreo sobre la importancia del desarrollo del proyecto, sus beneficios, y los compromisos que se deben asumir con el desarrollo de este, como el orientar a los niños al cuidado y no destrucción de los árboles y el reguío periódico de los árboles.

\section{Actividad 3.3. Forestación en el Municipio de Bosconia}

La actividad de forestación tomó tres días, de los cuales el primer día se realizó un reguío a todos los puntos de plantado con el apoyo del cuerpo de bomberos en horas de la noche con el fin de facilitar la actividad de ahoyado al día siguiente.

En el segundo día, se realizó el ahoyado en las zonas de muestreo con el apoyo de alcaldía, asorebos, BIOGER S.A, E.S.P y policía. La actividad se extendió por 5 horas y en base a la hora de finalización de la actividad se recomendó aplazar el plantado de los árboles debido a que la temperatura circundante no era apropiada.

En el tercer día, se procedió a realizar el sembrado en las zonas de muestreo con todos los criterios definidos en el plan de forestación, además de un posterior reguío en horas nocturnas.

\section{ANÁLISIS DE RESULTADOS}


En el análisis de la temperatura se encontró que la temperatura anual estimada para el municipio fue de $29^{\circ} \mathrm{C}$ en el año $2000,30^{\circ} \mathrm{C}$ para el año 2010 y $32^{\circ} \mathrm{C}$ para el año 2015 . Notándose que los índices de mayor temperatura se registran al oeste y sur oeste de la zona urbana, atribuido a las actividades mineras que se generan en esa zona de Bosconia que con los años han incrementado.

En el desarrollo del análisis del viento se pudo apreciar que no ha habido un cambio significativo desde los años 2000 hasta el 2015 en la zona urbana de Bosconia presentando velocidades de $2-5 \mathrm{~km} / \mathrm{h}$, debido a que las corrientes de aire son mayormente influenciadas por la topografía del terreno y la modificación estimada de la topografía ha sido de muy baja a nula.

En los análisis de sensación térmica se pudo determinar que para el año 2000 en la zona urbana central y sur se encontraron sensaciones térmicas de 2.24 a 2.26 y para la zona norte sensaciones térmicas de 2.26 a 2.27, determinándose que en el norte del municipio se presentaban las sensaciones térmicas más altas, dadas por la topografía del terreno.

Para el año 2010 se presentaron sensaciones de 1.69 a 1.78 en toda la zona urbana, dándose las mayores sensaciones térmicas al noroeste del Municipio, atribuidas a que la zona se utilizó la gran mayoría para cultivos de palma de aceite, deforestando las zonas de vegetación arbórea densa. Para el año 2015 se encontró que la sensación térmica se mantuvo en valores de 1.69 a 1.78, e igualmente las sensaciones térmicas más altas se mantuvieron al noroeste del Municipio.

Al momento de comparar los análisis de sensación térmica se puede apreciar el incremento del estrés térmico ya que entre más bajo sea el valor del índice de confort de sensación térmica hallado, más caluroso será el ambiente, quedando para este caso en el rango "incómodamente caluroso" (ver Tabla 1). Al momento de observar todos los años en conjunto con la información de los puntos de calor se identifica claramente el incremento de la radiación solar sobre la zona urbana de Bosconia siendo esta también influyente sobre nuestra percepción de sensación térmica. Este análisis satelital tiene un mayor grado de precisión que el de las estaciones meteorológicas porque se basa en puntos encontrados más cerca al área de interés, sin embargo, la comparación de ambos resultados tiene congruencia en su tendencia, ya que ambos indican un incremento de las sensaciones térmicas a través del tiempo en la zona de interés.

Para el año 2000 se encontró una cobertura arbórea poco golpeada por la agricultura hacia la zona norte, donde se presentó la mayor cantidad de cobertura arbórea. Para el año 2010 se presentó un significativo descenso en la cobertura forestal debido en su mayoría a la utilización de terrenos para cultivos mayoritariamente en toda la zona noroeste y para cultivos y ganadería en la zona noreste.

En el análisis del año 2015 se atribuyó este comportamiento de datos a la activación de actividades de minería en el Municipio hacia la zona sur. En el año 2020 se encontró un área significativa sin vegetación debido al incremento de las zonas donde la minería comenzó a tener impacto y la ejecución de las obras civiles nacionales y privadas que a la fecha siguen en desarrollo.

Al realizar el análisis multitemporal de los años seleccionados como representativos se pudo obtener que el descenso de vegetación arbórea desde el año 2000 hasta el año 2020 fue de 20694,51 ha, una importante cifra ya que representa el $33 \%$ del área total del Municipio. En su mayoría esta deforestación se ha debido al uso de grandes extensiones de área para la ganadería, el cual requiere la deforestación total de las áreas designadas para pastoreo, que generalmente en el Municipio son escogidas las de bosque natural fragmentado.

Otro uso de gran predominio del suelo en Bosconia es el del cultivo de palma de aceite, llegando a ser varias veces más grande que la ganadería en el Municipio, actividad que deforesta bosques naturales densos y bosques naturales fragmentados sin distinción. Entre actividades agrícolas, de minería y obras civiles se dio el área deforestada estimada.

Es resaltable que dentro del inventario forestal que se realizó con más de 300 árboles de forma aleatoria en Bosconia predominaron especies introducidas como olivo negro, neem y maíz tostao, Esto a causa de que 
por las características de crecimiento rápido o de copa frondosa amplia que presentan estas especies, la población en afán de reducir la sensación térmica que se genera en sus predios los siembra, sin tener en cuenta el impacto que se genera al ecosistema natural presente. El árbol de "Bálsamo" se llevó casi a su extinción debido a su aprovechamiento maderable en la construcción de la vía férrea, encontrado sólo tres especímenes de esta especie en el inventario forestal realizado.

\section{CONCLUSIONES}

Al momento de observar todos los años en conjunto con la información se identificó claramente el incremento de la problemática sobre la zona urbana de Bosconia. La comparación de los resultados tiene congruencia en su tendencia, ya que todos indican un incremento de las sensaciones térmicas a través del tiempo en la zona de interés.

La mitigación planteada a través de forestación del municipio de Bosconia promete reducir las altas sensaciones térmicas presentes y como se consideró el sembrado de especies nativas que son florales, además el embellecimiento del paisaje se admirarán al transitar con impactantes colores representativos de la región, y el sembrado de árboles para el paisajismo concientiza a las futuras generaciones del municipio de Bosconia tanto cultural como ambiental con un impacto ambiental positivo por una mayor captación de las emisiones producidas y una reducción de la sensación térmica presente.

\section{AGRADECIMIENTOS}

Los autores expresan sus agradecimientos a la alcaldía Municipal de Bosconia, cuerpo de bomberos, BIOGER S.A. E.S.P, defensa civil, policía ambiental, Universidad Popular del Cesar y al Ingeniero Hector Segura por sus aportes para la realización de esta investigación.

\section{REFERENCIAS BIBLIOGRÁFICAS}

[1] Departamento Administrativo Nacional de Estadística, DANE. (2018). Censo Nacional de Población y Vivienda - CNPV 2018 - DANE. https://www.dane.gov.co > CNPV-2018VIHOPE-v2

[2] Programa de las Naciones Unidas para el Desarrollo. (21 de agosto de 2015). Perfil productivo del municipio de Bosconia. https://issuu.com/pnudcol/docs/perfil_productivo_bosconia.

[3] Hernández et al. (2014). Metodología de la investigación. (sexta edición), Ciudad de Mèxico. McGraw-hill/ interamericana editores, S.A. DE C.V.

[4] Herrera, M. (2011). Formula para el calculo de la muestra poblaciones finitas. https://investigacionpediahr.files.wordpress.com/2011/01/formula-para-cc3a1lculo-de-la-muestra-

poblaciones-finitas-var-categorica.pdf

[5] Instituto de Hidrología, Meteorología y Estudios Ambientales - IDEAM. (2019). Catalogo Estaciones IDEAM. https://www.datos.gov.co/Ambiente-y-Desarrollo-Sostenible/CatalogoEstaciones-IDEAM/n6vw-vkfe

[6] Instituto de Hidrología, Meteorología y Estudios Ambientales - IDEAM. (1998). Metodología para el cálculo del confort climático. Santa $\mathrm{Fe}$ de Bogotá. http://documentacion.ideam.gov.co/openbiblio/bvirtual/007574/Metodologiaconfort.pdf 
[7] Tumini, I. (2012). El microclima urbano en los espacios abiertos: Estudios de casos en Madrid. [Tesis de Doctorado, Universidad Politécnica de Madrid]. Repositorio upm. http://oa.upm.es/14893/

[8] Hernández et al. (2018). Bosque seco tropical: guía de especies. Instituto de Investigación de Recursos Biológicos Alexander von Humboldt. Repositorio Institucional de Documentación Científica. http://repository.humboldt.org.co/handle/20.500.11761/35305

[9] Alcárcel, F.A. \& Gómez, J., compiladores. (2019). Mapa Geológico de Colombia 2019. Escala $\quad 1: 2 \quad 000 \quad 000 . \quad$ Servicio Geológico Colombiano. Bogotá. https://www2.sgc.gov.co/MGC/Paginas/mgc2M2019.aspx

[10] Boada, M., \& Chavarro, S. (2006). Evaluación hidrogeológica y ambiental del potencial del agua subterránea en la cabecera y área de influencia rural en Bosconia, Cesar. [Trabajo de grado de pregrado, Universidad de La Salle] Repositorio Institucional-Ciencia Unisalle. Obtenido de https://ciencia.lasalle.edu.co/ing_ambiental_sanitaria/398 